PREPARED FOR THE U.S. DEPARTMENT OF ENERGY, UNDER CONTRACT DE-AC02-76CH03073

PPPL-3585

PPPL-3585

UC-70

Comparison of Theory with Rotation Measurements in JET ICRH Plasmas

by

R.V. Budny, C.S. Chang, C. Giroud, R.J. Goldston, D. McCune, J. Ongena, F.W. Perkins, R.B. White, K.-D. Zastrow, and contributors to the EFDA-JET work programme

June 2001

NM|

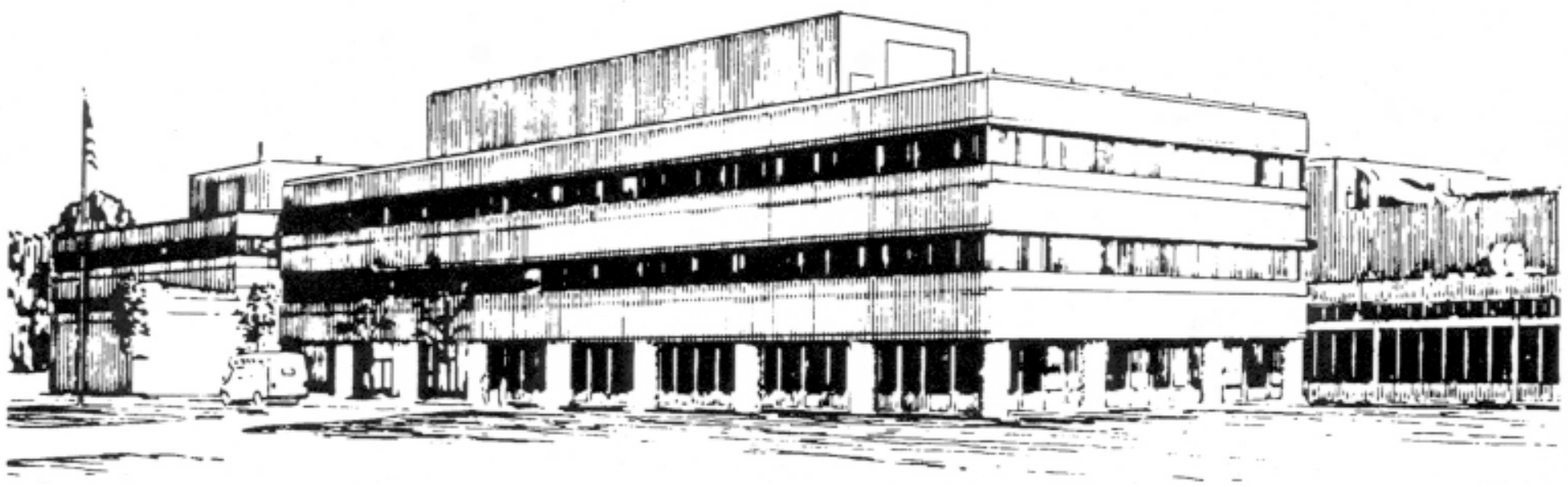

PRINCETON PLASMA PHYSICS LABORATORY PRINCETON UNIVERSITY, PRINCETON, NEW JERSEY 


\section{PPPL Reports Disclaimer}

This report was prepared as an account of work sponsored by an agency of the United States Government. Neither the United States Government nor any agency thereof, nor any of their employees, makes any warranty, express or implied, or assumes any legal liability or responsibility for the accuracy, completeness, or usefulness of any information, apparatus, product, or process disclosed, or represents that its use would not infringe privately owned rights. Reference herein to any specific commercial product, process, or service by trade name, trademark, manufacturer, or otherwise, does not necessarily constitute or imply its endorsement, recommendation, or favoring by the United States Government or any agency thereof. The views and opinions of authors expressed herein do not necessarily state or reflect those of the United States Government or any agency thereof.

\section{Availability}

This report is posted on the U.S. Department of Energy's Princeton Plasma Physics Laboratory Publications and Reports web site in Calendar Year 2001. The home page for PPPL Reports and Publications is: http://www.pppl.gov/pub_report/

DOE and DOE Contractors can obtain copies of this report from:

U.S. Department of Energy

Office of Scientific and Technical Information

DOE Technical Information Services (DTIS)

P.O. Box 62

Oak Ridge, TN 37831

Telephone: (865) 576-8401

Fax: (865) 576-5728

Email: reports@adonis.osti.gov

This report is available to the general public from:

National Technical Information Service

U.S. Department of Commerce

5285 Port Royal Road

Springfield, VA 22161

Telephone: 1-800-553-6847 or

(703) 605-6000

Fax: (703) 321-8547

Internet: http://www.ntis.gov/ordering.htm 


\title{
COMPARISON OF THEORY WITH ROTATION MEASUREMENTS IN JET ICRH PLASMAS ${ }^{a}$
}

\author{
R.V. Budny ${ }^{\star}$, C.S. Chang ${ }^{\ddagger}$, C. Giroud ${ }^{*}$, R.J. Goldston ${ }^{\star}$, C. Gowers*, D. McCune ${ }^{\star}$, \\ J. Ongena ${ }^{\diamond}$, F.W. Perkins ${ }^{\star}$, R.B. White ${ }^{\star}$, K.-D. Zastrow*, \\ and contributors to the EFDA-JET workprogramme ${ }^{b}$ \\ ^Princeton Plasma Physics Laboratory, P.O. Box 451, Princeton, NJ 08543, USA, \\ ${ }^{\ddagger}$ Courant Institute, New York University, NY, NY 10012, USA, \\ ${ }^{\circ} \mathrm{LPP}-\mathrm{ERM} / \mathrm{KMS}$, Association "EURATOM-Belgian State", Brussels, Belgium, \\ *Euratom/UKAEA Fusion Association, Culham Science Center, OX14 3DB, UK
}

1 - Introduction Plasma rotation appears to improve plasma performance by increasing the $\mathrm{E} \times \mathrm{B}$ flow shearing rate, thus decreasing radial correlations in the microturbulence. Also plasma rotation can increase the stability to resistive MHD modes. In JET, toroidal rotation rates $\omega_{\text {tor }}$ with high Mach numbers are generally measured in NBI-heated plasmas (since the neutral beams aim in the co-plasma current direction). They are considerably lower with only ICRH (and Ohmic) heating, but still surprisingly large considering that ICRH appears to inject relatively small amounts of angular momentum. Either the applied torques are larger than naively expected, or the anomalous transport of angular momentum is smaller than expected. Since ICRH is one of the main candidates for heating next-step Tokamaks, and for creating burning plasmas in future Tokamak reactors, this paper attempts to understand ICRH-induced plasma rotation.

The spin-up in the core region during the diagnostic NBI is in quantitative agreement with the NBI torques. The steady rotation near the pedestal is in qualitative agreement with a theory of X-point ion loss. The largest steady rotation, measured near the outer mid-radius, is too large in magnitude and has the wrong sign (positive) for the inboard resonance plasmas to be explained by the theoretically proposed ICRH-induced torques.

2 - Experiments Recent experiments in JET have produced careful measurements of $\omega_{\text {tor }}[1,2]$, and preliminary measurements of poloidal rotation profiles $\mathrm{v}_{\text {pol }}[3]$ of the carbon impurity in a variety of plasma conditions with $\mathrm{H}$-minority ICRH schemes. Brief blips of NBI are used for the charge-exchange measurements of $T_{i}, Z_{e f f}$, and $\omega_{t o r}$. The $\omega_{t o r}$ measurements are corroborated with measurements from the Doppler broadening and shift of Ni emission lines and with the frequency of MHD modes.

Waveforms for a JET deuterium plasma are shown in Fig.1a. This plasma is one of four [2] in which the ICRH resonance layer was tuned to be either inboard or outboard of the major radius of the magnetic axis, and the relative phasing of the four ICRH antenna was altered between either $+\pi / 2$ or $-\pi / 2$. The spectrum of toroidal wavenumber of the ICRH waves for the $+\pi / 2$ case is calculated to peak at $k_{\|}=+4 / \mathrm{m}$ and $-10 / \mathrm{m}$, and for the $-\pi / 2$ case to peak at $k_{\|}=-4 / \mathrm{m}$ and $+10 / \mathrm{m}[2]$. At $18.4 \mathrm{~s}$, the central $\mathrm{T}_{i}, \mathrm{~T}_{e}, \mathrm{n}_{e}$, and $\mathrm{Z}_{\text {eff }}$ are $2.2[\mathrm{keV}], 2.5[\mathrm{keV}], 3 \times 10^{19}\left[\mathrm{~m}^{-3}\right]$, and 1.5 .

These four very-similar plasmas had relatively low energy confinement, remaining in L-mode for most of their durations. Examples of $\omega_{\text {tor }}$ during the first NBI blip are shown in Fig.1b. Even though the NBI power was kept low to minimize the NBI torque, the NBI tends to spin-up $\omega_{\text {tor }}$ near the magnetic axis $[1,2]$. $\omega_{\text {tor }}$ peaks near the midradius, in the region between the computed $q=1$ surface $(R \simeq 3.3 \mathrm{~m})$ and the $q=3$ surface, $(\mathrm{R} \simeq 3.73 \mathrm{~m})$, and where the measured carbon density peaks. The Mach number (ratio of $\mathrm{v}_{\text {tor }}$ and thermal speed) is near 0.22 at the peak, and sufficiently high to dominate over the pressure gradient and neo-classical $\mathrm{v}_{\text {pol }}$ contributions to $\mathrm{E}_{r}$. In ELMy H-mode plasmas, the $\omega_{\text {tor }}$ profiles also tend to be broad, co-rotating in the direction of the plasma current and toroidal field with peak magnitude about 15 per cent of that measured in similar NBI-only plasmas [1]. The measured $\omega_{\text {tor }}$ tend to decrease as the perpendicular temperature of the H-minority ions increases. 

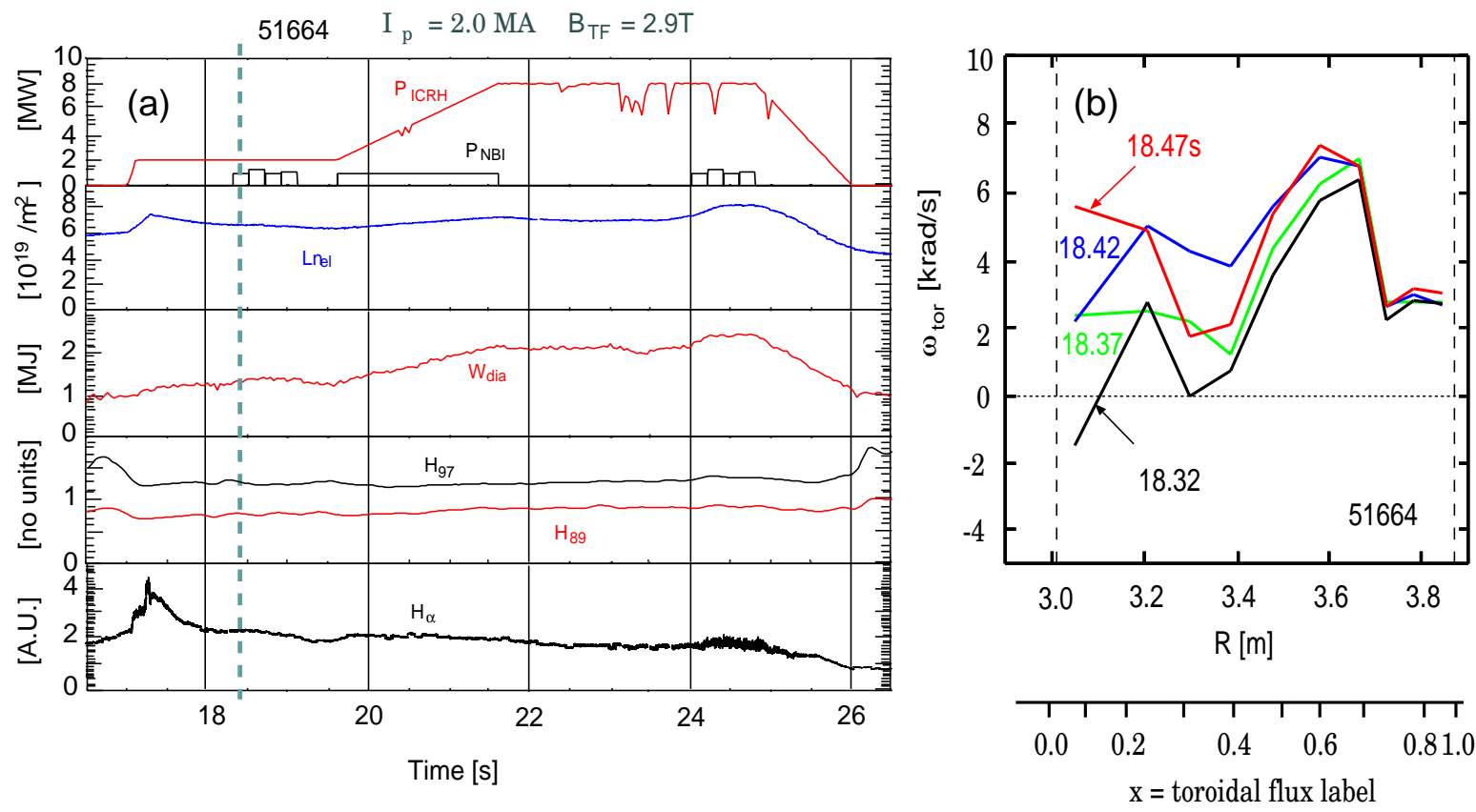

FIG. 1.: a) Waveforms and b) rotation profiles of one of the four similar plasmas studied near 18.4s

3 - NBI torques and anomalous angular momentum transport - Three classes of torques are considered: $T_{N B}, T_{R F}$, and $T_{X}$ caused by the NBI, ICRH, and ion loss near the X-point. For the plasmas studied, these torques are largest in the core, mid-radius, and near the pedestal, respectively. The increase of $\omega_{\text {tor }}$ near the axis can be understood from $T_{N B}$. The TRANSP plasma analysis code uses Monte Carlo techniques to calculate $T_{N B}$ as the sum of the collisional, $\mathrm{J} \times \mathrm{B}$, ripple loss, and thermalization torques, shown in Fig.2a. The collisional torque dominates in the core, and is approximately the same magnitude as the $\mathrm{J} \times \mathrm{B}$ torque outside the core region. The thermalization torque is small for brief NBI blips, and the ripple-loss torque is negligible in JET. $T_{N B}$ is close to the measured rate of increase of the angular momentum density $\mathrm{mR}^{2} \omega_{\text {tor }}$ during the NBI. This confirms that the rotation measured for the carbon is about the same as that of the bulk deuterium, at least in the core. The volume-integral of $T_{N B}$ increases roughly linearly with the toroidal flux label $\mathrm{x}=\sqrt{ }($ normalized toroidal flux $)$ to $\simeq 0.5$ [Nt-m] at the $\mathrm{q}_{98}$ flux surface $(\mathrm{x}=1)$. The volume integrals of mass and $\mathrm{mR}^{2} \omega_{\text {tor }}$ during the NBI blip peak at $4[\mathrm{mgm}]$ and $0.004\left[\mathrm{Nt}-\mathrm{s} / \mathrm{m}^{2}\right]$ respectively.
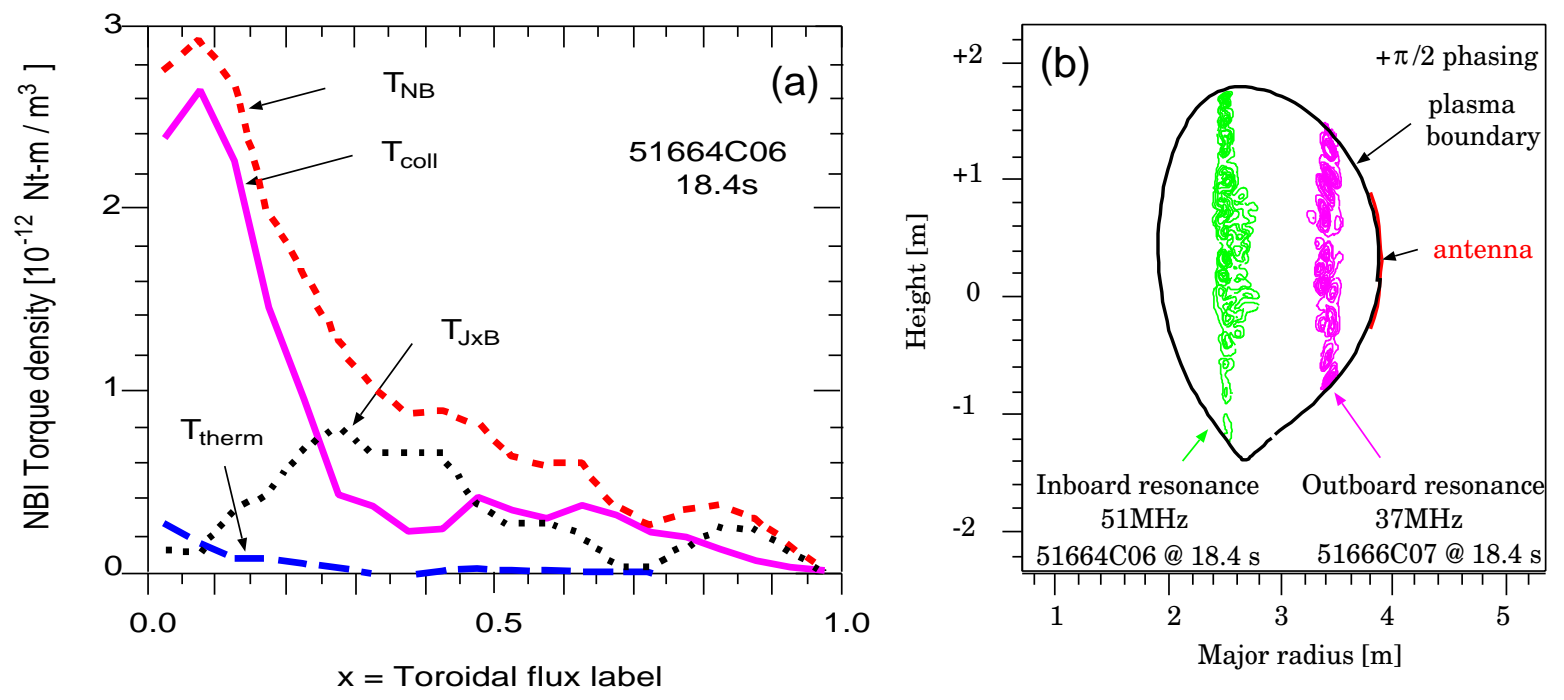

FIG. 2.: a) TRANSP NBI torques and b) TRANSP/SPRUCE ICRH power depositions in two plasmas 
The decay rate of the central angular momentum after the NBI measures the central anomalous angular momentum transport, $\chi_{\text {tor }}$. JET plasmas with NBI-only heating have $\chi_{\text {tor }} \approx 0.5 \chi_{i}$. Using $\chi_{\text {tor }}$ around 1-5 times $\chi_{i}$ in TRANSP gives roughly the measured decay rate.

4 - ICRH power deposition - The SPRUCE [4] modules in TRANSP are used to calculate the ICRH interactions. Typically the 2D grid has 256 radial and 128 poloidal nodes. The electromagnetic waves are modeled approximating $k_{||}$with two symmetricallyplaced peaks at $\pm 10 / \mathrm{m}$. The actual asymmetry in the spectra is not modeled since $\omega_{\text {tor }}$ appears to be very comparable for all of the four plasmas. SPRUCE calculates that 90 per cent of the ICRH power is absorbed by the H-minority, 8 percent by the D ions, and 2 per cent by the electrons. Contours of the heating for one of the inboard and outboard plasmas are shown in Fig.2b. The heating of the thermal plasma by the fast ions is also computed by TRANSP. The distributions of the ICRH power deposition along the vertical position on the resonance surface are very similar for the four plasmas, approximately proportional to $\exp \left[-(y-0.4)^{2}\right]$ where $\mathrm{y}[\mathrm{m}]$ is the height in the plasma.

5 - ICRH-Induced Rotation - Recent theories of ICRH-induced toroidal rotation have been applied to measurements of central $\omega_{\text {tor }}$ in Alcator-CMOD [5,6]. This paper extends and tests these theories using detailed modeling of the ICRH power deposition on the minority ions in the highly shaped, up/down asymmetric flux surfaces in the JET plasmas discussed above.

The distributions of the ICRH power deposition along the vertical position on the resonance surface are used in the ORBIT Monte Carlo Hamiltonian code [7] to calculate the neoclassical trajectories of the heated ion guiding centers. The H-minority ions are launched with a fixed energy $(2 \mathrm{keV})$ and with a uniform distribution in pitch angle in the region of space where their orbits intersect with the resonance layer. Their energies are increased as they pass through the layer, while they slow down and pitch angle scatter during the rest of their orbit. This is continued until they obtain the average (perpendicular) energy given by the SPRUCE modeling $(\simeq 20-80 \mathrm{keV})$.

As the fast ions pitch-angle scatter, their radial displacements cause a compensating current in the thermal plasma. The $R j_{r} B_{\text {pol }}$ torque generates plasma rotation. Also the collisional slowing-down of the fast ions deposits angular momentum to the thermal plasma. In ORBIT, these effects are computed by subtracting the net torque with ICRH heating from the result without the heating. The pitch-angle scattering effect is about three times the slowing down drag term. A non-dimensional function $\mathrm{I}(\mathrm{x})$ was introduced in Ref. 6 for the net toroidal rotation. Profiles for the four plasmas are shown in Fig.3a. These functions depend only weakly on the value of the average perpendicular energy assumed. The rotation is assumed to be zero (no slip) at the plasma boundary $(\mathrm{x}=1)$. The conversion of $\mathrm{I}(\mathrm{x})$ to the rotation frequency profile is given by :

$$
\frac{\omega_{\text {tor }}}{I}=\left[\frac{C_{n} W}{e B R^{3} a^{2} \bar{n}(2 \pi)^{2}}\left(\frac{\tau_{\text {mom }}}{\tau_{E}}\right)\right]
$$

Here $\mathrm{W}$ is the total energy, and $\mathrm{C}_{n}$ is a parameterization of $\chi_{\text {tor }}$ as $\mathrm{C}_{n} q^{n}$. We use $\mathrm{C}_{n}=4$. The factor $\tau_{m o m} / \tau_{E}$ is the ratio of the confinement times for the toroidal angular momentum and energy. This is expected to be of order $\chi_{\mathrm{i}} / \chi_{\text {tor }}$, which tends to be approximately 4 near the mid radius of JET ELMy H-mode plasmas with NBI-only heating. Thus we assume $\tau_{m o m} / \tau_{E}=4$. The resulting estimation of $\omega_{\text {tor }} / I$ is approximately $10^{3} / \mathrm{s}$. Multiplying by $\mathrm{I}(\mathrm{x})$ in Fig.3a gives the magnitude of $\omega_{\text {tor }}$ too small in magnitude and with the wrong sign in the case of the inboard resonance layer. The corresponding profiles of $\mathrm{I}(\mathrm{x})$ for a CMOD plasma with off-axis ICRH, shown in Ref. [6] are similar in magnitude to the JET results. 

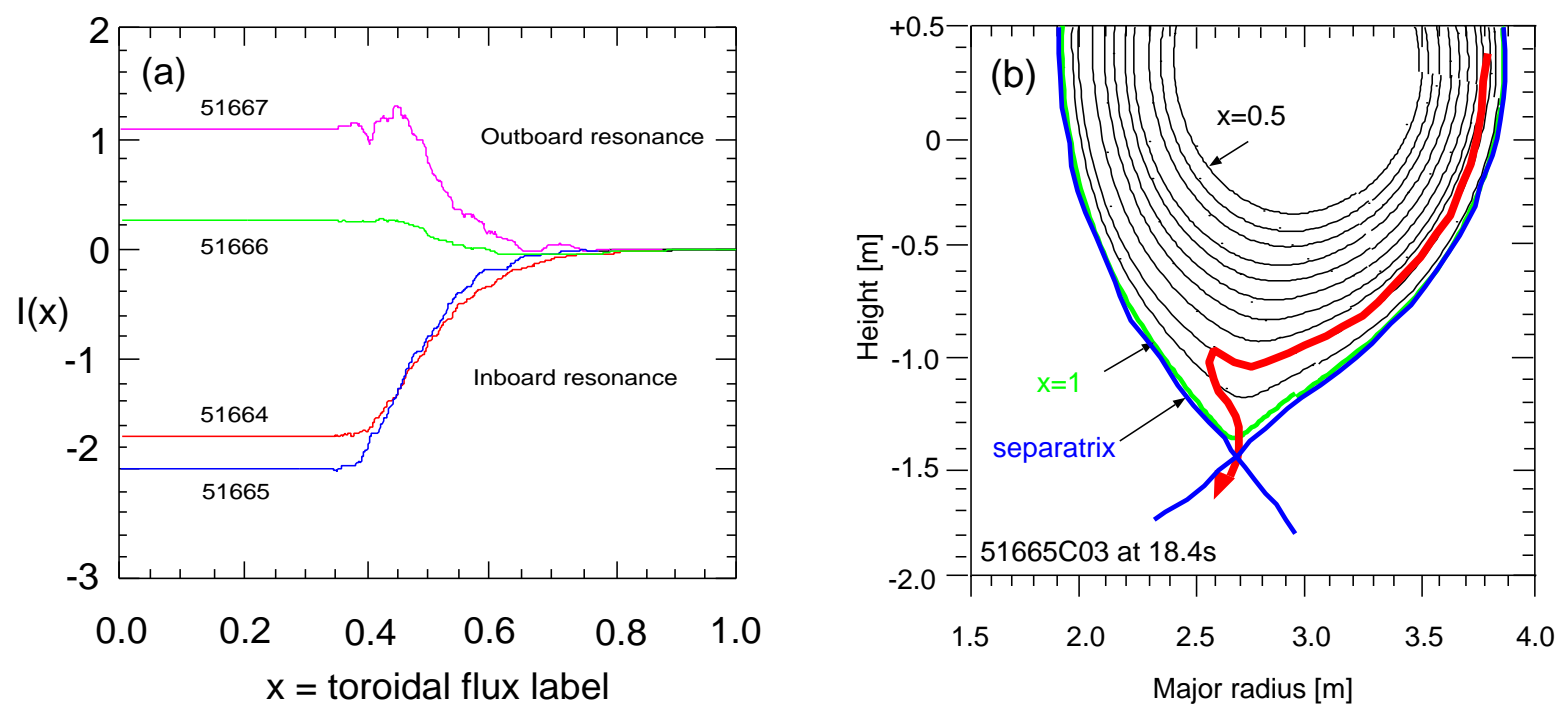

FIG. 3.: a) Non-dimensional I(x) from ORBIT and b) schematic orbit of an X-point lost ion

Part of the discrepancy for the outboard cases might be due to the no-slip assumption. The measurements in Fig.1b show a systematic offset of about 3 kradians/s near the pedestal. If the predicted rotation rate is scaled up by this offset, the magnitude would be in closer agreement, but the sign remains wrong for the inboard resonance.

6 - X-point Ion Loss - Since $B_{\text {pol }}$ vanishes near the X-point, ions with small and negative $\mathrm{v}_{\text {tor }}$ are not expected to be confined there [8]. For these JET plasmas, the collisionless hole in velocity space $8 \mathrm{~cm}$ above the $\mathrm{X}$-point is calculated to have a minimum loss energy of $\simeq 0.5 \mathrm{keV}$. A collisionless lost ion orbit is shown in Fig. $3 \mathrm{~b}$. Two adjacent radial layers are expected to form under the X-loss region. Collisionless loss of counter traveling ions becomes a source of co-torque at the minor radius just inside the pedestal layer, while the $\mathrm{j}_{r} \times \mathrm{B}$ force by the plasma return current creates a strong, negative radial $\mathrm{E}_{r}$ layer within this thin pedestal layer. Modeled in the form of a delta function at the pedestal radius $\mathrm{r}_{h}$, the co-rotation torque density is evaluated to be $\simeq 1 \times 10^{-11} \times \delta\left(r-r_{h}\right)\left[N-m / m^{3}\right]$, which can be a significant source of co-rotation near the edge.

7 - Discussion - Three classes of torques contributing to the toroidal angular momentum measured in four plasmas with ICRH heating have been studied. Combined with estimates of $\chi_{t o r}$, the torques from the NBI are sufficient to explain the spin-up and decay of of $\omega_{\text {tor }}$ near the magnetic axis. The torque from the ICRH is calculated to be too small and to have the wrong sign for the peak in $\omega_{\text {tor }}$ measured near the mid-radius. The large positive offset of $\omega_{\text {tor }}$ near the pedestal is qualitatively consistent with a new theory of X-point ion loss. Both the ICRH and X-point loss torques generate both toroidal and poloidal torques. The torques from $r j_{r} B_{\text {tor }}$ and estimates of collisional damping can be used to estimate the poloidal rotation speed $\mathrm{v}_{\text {pol }}$ and to compare with preliminary measurements in JET.

${ }^{a}$ This work has been conducted under the European Fusion Development Agreement and supported in part by the US DoE Contract No. DE-ACO2-76CHO3073.

${ }^{b}$ see appendix of J. Pamela, "Overview of recent JET results", IAEA, Sorrento, 2000

[1] R.V. Budny, et al., APS, Quebec, (2000), http://w3.pppl.gov/ budny/JG00.293.pdf

2 J.-M. Noterdaeme, et al., RF conference, Oxnard, Cal, USA (2001)

3. F. Suttin, et al., 28th EPS, Madeira (2001)

4. M. Evrard, J. Ongena, and D. Van Eester, RF conference, Palm Springs (1995)

5 C.S. Chang, P.T. Bonoli, J.E. Rice, et al., Phys of Plasma, 7, 1089 (2000).

6 F.W. Perkins, R.B. White, P. Bonoli, and V. Chan, Phys. of Plasmas 8, 2181 (2001).

7. R. B. White and M. S. Chance, Phys. Fluids 27, 2455 (1984)

[8] C. S. Chang, et al., IAEA, Sorrento, 2001 


\section{External Distribution}

Plasma Research Laboratory, Australian National University, Australia

Professor I.R. J ones, Flinders University, Australia

Professor J oão Canalle, Instituto de Fisica DEQ/IF - UERJ , Brazil

Mr. Gerson O. Ludwig, Instituto Nacional de Pesquisas, Brazil

Dr. P.H. Sakanaka, Instituto Fisica, Brazil

The Librarian, Culham Laboratory, England

Library, R61, Rutherford Appleton Laboratory, England

Mrs. S.A. Hutchinson, JET Library, England

Professor M.N. Bussac, Ecole Polytechnique, France

Librarian, Max-Planck-Institut für Plasmaphysik, Germany

J olan Moldvai, Reports Library, MTA KFKI-ATKI, Hungary

Dr. P. Kaw, Institute for Plasma Research, India

Ms. P.J . Pathak, Librarian, Insitute for Plasma Research, India

Ms. Clelia De Palo, Associazione EURATOM-ENEA, I taly

Dr. G. Grosso, Instituto di Fisica del Plasma, Italy

Librarian, Naka Fusion Research Establishment, J AERI, J apan

Library, Plasma Physics Laboratory, Kyoto University, J apan

Research Information Center, National Institute for Fusion Science, J apan

Dr. O. Mitarai, Kyushu Tokai University, J apan

Library, Academia Sinica, Institute of Plasma Physics, People's Republic of China

Shih-Tung Tsai, Institute of Physics, Chinese Academy of Sciences, People's Republic of China

Dr. S. Mirnov, TRINITI, Troitsk, Russian Federation, Russia

Dr. V.S. Strelkov, Kurchatov Institute, Russian Federation, Russia

Professor Peter Lukac, Katedra Fyziky Plazmy MFF UK, Mlynska dolina F-2, Komenskeho Univerzita, SK-842 15 Bratislava, Slovakia

Dr. G.S. Lee, Korea Basic Science Institute, South Korea

Mr. Dennis Bruggink, Fusion Library, University of Wisconsin, USA

Institute for Plasma Research, University of Maryland, USA

Librarian, Fusion Energy Division, Oak Ridge National Laboratory, USA

Librarian, Institute of Fusion Studies, University of Texas, USA

Librarian, Magnetic Fusion Program, Lawrence Livermore National Laboratory, USA

Library, General Atomics, USA

Plasma Physics Group, Fusion Energy Research Program, University of California at San Diego, USA

Plasma Physics Library, Columbia University, USA

Alkesh Punjabi, Center for Fusion Research and Training, Hampton University, USA

Dr. W.M. Stacey, Fusion Research Center, Georgia Institute of Technology, USA

Dr. J ohn Willis, U.S. Department of Energy, Office of Fusion Energy Sciences, USA

Mr. Paul H. Wright, Indianapolis, Indiana, USA 
The Princeton Plasma Physics Laboratory is operated by Princeton University under contract with the U.S. Department of Energy.

\author{
Information Services \\ Princeton Plasma Physics Laboratory \\ P.O. Box 451 \\ Princeton, NJ 08543
}

Phone: 609-243-2750

Fax: 609-243-2751

e-mail: pppl_info@pppl.gov

Internet Address: http://www.pppl.gov 